\title{
A model for the biosynthesis and transport of plasma membrane-associated signaling receptors to the cell surface
}

\author{
Sorina C. Popescu * \\ Boyce Thompson Institute for Plant Research, Ithaca, NY, USA
}

\section{Edited by: \\ Jay Thelen, University of Missouri, USA}

\section{Reviewed by:}

Ján A. Miernyk, University of

Missouri, USA

Ian Max Møller, Aarhus University,

Denmark

Antje Heese, University of

Missouri-Columbia, USA

${ }^{*}$ Correspondence:

Sorina C. Popescu, Boyce Thompson Institute for Plant Research, Tower

Road, Ithaca, NY 14853, USA.

e-mail: scp78@cornell.edu
Intracellular protein transport is emerging as critical in determining the outcome of receptoractivated signal transduction pathways. In plants, relatively little is known about the nature of the molecular components and mechanisms involved in coordinating receptor synthesis and transport to the cell surface. Recent advances in this field indicate that signaling pathways and intracellular transport machinery converge and coordinate to render receptors competent for signaling at their plasma membrane (PM) activity sites. The biogenesis and transport to the cell surface of signaling receptors appears to require both general trafficking and receptor-specific factors. Several molecular determinants, residing or associated with compartments of the secretory pathway and known to influence aspects in receptor biogenesis, are discussed and integrated into a predictive cooperative model for the functional expression of signaling receptors at the PM.

Keywords: plasma membrane, endoplasmic reticulum, receptor-accesory protein, signaling receptor, anterograde transport

\section{INTRODUCTION}

Eukaryotes are able to cope with the dynamic variations in their surrounding environment by activating intracellular signal transduction pathways. Transmembrane receptor proteins associated with the plasma membrane (PM) are the primary elements in signaling pathways and therefore perform key functions in organism survival. PM receptors perceive and are activated by extrinsic ligands such as bacterial molecules or intrinsic cellular signals. Once activated, PM receptors auto-phosphorylate and recruit and phosphorylate other proteins, triggering intracellular signal transduction cascades (Zipfel, 2008; Boller and Felix, 2009). Signaling cascades phosphorylate intracellular proteins causing changes in their abundance and activity, and modify the gene expression program of the cell to elicit specific physiological responses (Aker and de Vries, 2008; Tor et al., 2009; Bethani et al., 2010). While receptor ligands, activation manner, and the derivative signaling pathways have been characterized for a number of plant receptors, the mechanisms that govern the functional expression of receptors at their membrane site of action are less understood. In particular, the events that lead to the transport of receptors to the PM and the regulation of these events in response to cellular and environmental cues are largely unknown in plants.

Intracellular transport of proteins involves a network of membranous compartments connected by transport vesicles and other transport structures. Both soluble proteins and proteins containing hydrophobic transmembrane domains rely on the general protein trafficking machinery for delivery via the secretory (also called "anterograde") pathway to their final destinations. In plants, the endoplasmic reticulum (ER), Golgi complex, and trans-Golgi network (TGN) form the secretory transport conduit. In addition, a large number of organelle-associated proteins and lipids confer compartment identity, perform inter- and intracompartment transport, and guide the trafficking of protein cargo (Carter et al., 2004; Jurgens, 2004; Dunkley et al., 2006). The transport of proteins within the plant secretory pathway is a dynamic and complex process. In the ER, membrane proteins destined for secretion accumulate in transport vesicles coated with the coat protein complex-II (COPII), which then bud from the ER-exit sites (ERESs). The COPII vesicles capture the mobile Golgi stacks from the cytosol and transfer their contents into the Golgi complex (Brandizzi et al., 2002; Runions et al., 2006; Staehelin and Kang, 2008). The transport factors that guide proteins from the ER to the Golgi return to the ER via coat protein complex-I (COPI)coated vesicles (Stefano et al., 2006). As proteins progress through the Golgi, they undergo the final maturation steps and are subsequently transferred to the TGN, a sorting station which releases proteins to the PM (Staehelin and Kang, 2008). Targeted fusion of transport vesicles with the PM is facilitated by an octameric complex, the exocyst (Hala et al., 2008; Zhang et al., 2010).

Given its inherent functions, the secretory pathway modulates the spatial and temporal distribution of a large fraction of cellular signaling elements, including receptors, co-receptors, and other associated components. It is generally accepted that plant PM-associated signaling receptors rely on the constitutive, generic secretory transport route to mature and reach destination sites on membranes (Rojo and Denecke, 2008; Cai et al., 2011). Nevertheless, the critical roles of the receptors in the cell along with the diversity in their functional and structural characteristics strongly argue for a high degree of flexibility in their biosynthesis and delivery to the activity sites. In yeast and animals, several factors under the control of the secretion process including the cellular amount of receptor molecules, intracellular 
compartmentalization, and the steady-state distribution and density of receptors at the PM, were found to govern the signaling specificity, amplitude, and the nature of the physiological output. Moreover, a highly regulated secretion process that guides the secretion of PM receptors was described in humans. This regulated secretion process was found to employ elements of the generic transport machinery but also to recruit additional receptor-specific components. The recruited proteins physically associate with nascent receptors and act as an interface between the receptor and the secretion machinery respond to relevant changes in the cellular environment. For example, events including the presence of ligands and accumulation of secondary messengers such as calcium ions, impact the efficiency of receptor secretion rate, and introduce additional checkpoints for its regulation. These and additional aspects of the PM receptor secretion in eukaryotic systems other than plants, have been described in numerous reviews (Mellman and Nelson, 2008; Cooray et al., 2009; Winckler and Mellman, 2010; Shilo and Schejter, 2011). It is clear that regardless of the receptors' cellular function, structural characteristics or organism of origin, highly controlled and efficient pathways for the production and transport to the PM is a common requirement.

Whether such a regulated secretory process exists in plants to mediate the transport of PM-associated receptors is still an open question. Nevertheless, evidence accumulated over recent years argues for an important role of secretion in modulating the signaling functions of plant receptors. For instance, the steadystate levels of accumulation at the PM of one of the known tomato ethylene receptors (LeETR4) or of the Arabidopsis flagellin receptor (FLS2), correlated with the strength of their signaling output following activation by ligands. Suppression of LeETR4 expression by RNAi resulted in an early-ripening tomato fruit (Kevany et al., 2008); likewise, reduced FLS2 accumulation at the PM impaired the accumulation of reactive oxygen species (Boutrot et al., 2010; Mersmann et al., 2010). Moreover, quantification of the cellular levels of BRI1, brassinosteroid receptor (Li and Chory, 1997), revealed that BRI1 accumulated at the PM in an organ-dependent manner (Harter and Witthhoft, 2011; van Esse et al., 2011). Furthermore, a number of plant receptor-interacting proteins belonging to various classes have been discovered by recent work and shown to influence the biosynthesis, transport, and functional performance of receptors at the PM.

This article will discuss two aspects of receptor trafficking to the PM: (I) the role of ER and the ER-associated factors in the maturation and quality control of nascent receptors for release into the secretory pathway, and (II) a potential model for the transport of plant receptors out of the ER to the cell surface (Figure 1).

\section{ENDOPLASMIC RETICULUM - A HUB FOR RECEPTOR BIOGENESIS AND MATURATION IN THE EARLY SECRETORY PATHWAY}

The anterograde transport of proteins is coupled with the process of protein maturation which occurs in the ER. Maturation includes the correct folding and the addition of post-translational modifications to newly synthesized polypeptides (Jurgens, 2004; Staehelin and Kang, 2008). Newly synthesized transmembrane proteins enter the secretory pathway at the ER, following translocation into the ER membrane via the translocon complex (Agarraberes and Dice, 2001; Rapoport, 2007). The ER proteome is enriched in molecular chaperones that promote the correct folding and glycosylation of imported proteins (Molinari and Helenius, 2000; Kleizen and Braakman, 2004). ER chaperones recruit nascent membrane proteins by binding to their exposed ER-retention domains, hydrophobic regions, or glycosylation motifs (Reddy and Corley, 1998; Smith et al., 2011). The recent work describing the role of several plant ER molecular chaperones in receptor maturation or export out of the ER is outlined below (Table 1).

\section{CALNEXINS AND CALRETICULINS ARE ER CHAPERONES THAT BLOCK THE EXPORT OF DEFECTIVE RECEPTORS OUT OF THE ER}

The ER-localized chaperone calnexin was reported to interact with the defective BRI1-5 but not the wild type BRI1 receptor (Hong et al., 2008). Another BRI1 mutant, BRI1-9, was coimmunoprecipitated with Arabidopsis calnexin and calreticulin (CRT) isoforms, and was retained in the ER through the association with ER chaperones (Jin et al., 2007). More recently, BRI1-9 and CRT3 were found to interact in the ER (Jin et al., 2009). It is likely that calnexin and calreticulin isoforms may control the maturation of other receptors as well.

\section{ER-LOCALIZED HEAT SHOCK PROTEIN 70 HOMOLOGS REGULATE THE MATURATION OF BRI1 AND THE RICE RECEPTOR XA21}

BiP, an Arabidopsis ER-localized chaperone from the heat shock protein (HSP) 70 family participates in the ER-associated quality control (ERQC) of BRI1 by interacting and retaining the defective BRI1-9 in the ER (Jin et al., 2007). Similarly, in rice OsBiP3 interacts with the PM receptor XA21 (Park et al., 2010). In BiP3 gain-of-function transgenic rice, both the stability and proteolytic cleavage of XA21 were impaired, compromising XA21-mediated immunity. Interestingly, although XA21 recognizes its ligand at the PM, the bulk of XA21 receptors expressed from the native promoter localized at the ER (Park et al., 2010), suggesting that XA21 accumulates at the ER to be readily released when needed. A similar strategy is used by human cells to sequester receptors in compartments of the secretory pathway for the "on-demand" delivery (Ascano et al., 2009). Since XA21 expressed from the $35 \mathrm{~S}$ CaMV constitutive promoter localized at the PM (Chen et al., 2010a), this possible regulatory step may be overridden by the XA21 overexpression.

\section{HOP/STI1 AND HSP90: A CHAPERONE COMPLEX REOUIRED FOR THE ANTEROGRADE TRANSPORT OF THE RICE OSCERK1 CHITIN RECEPTOR}

In a recent study, the rice receptor for chitin, OsCERK1, was found to interact in rice protoplasts with HSP90 and the HOP/STI1 cochaperones (Chen et al., 2010b). Bimolecular fluorescence assays designated both the ER and PM as interaction sites, suggesting that the HOP/STI1-HSP90 complex is required for export of OsCERK1 from the ER, and may co-travel with OsCERK1 to the PM via the secretory pathway dependent on the small GTPase SAR1 (Chen et al., 2010b). Hop/Stil-RNAi mutants were more susceptible to a virulent strain of the rice blast fungus compared to controls, whereas overexpression of HOP/STI1 conferred resistance. 


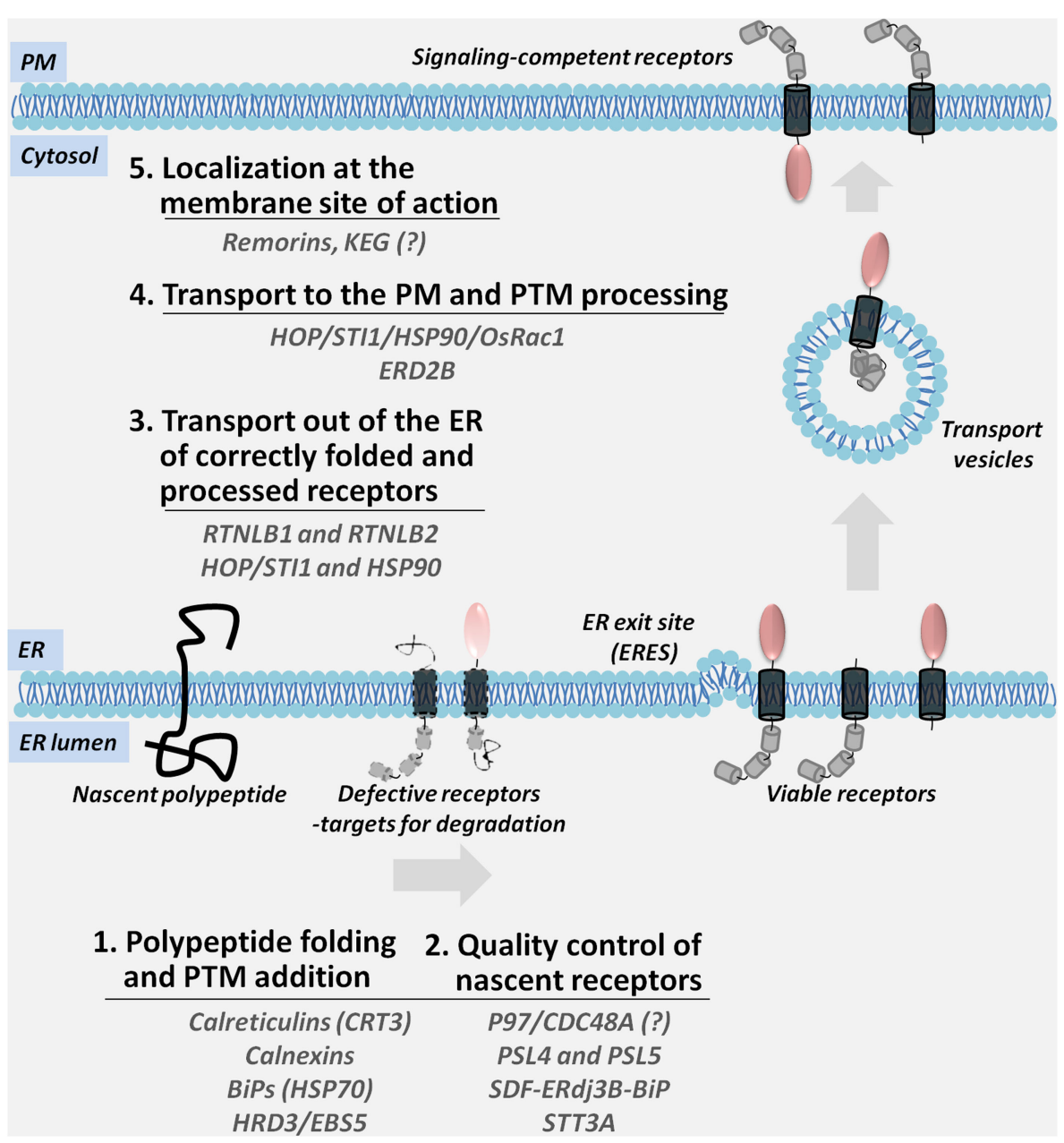

FIGURE 1 | A multi-step model for the ER-to-PM biosynthesis and trafficking of PM-associated signaling receptors. Nascent polypeptides are translocated into the ER membrane where they are subjected to the ER-resident folding and post-translational modification (PTM) machinery; defective receptors are recognized by the components of the ER quality control and directed for degradation (Steps 1 and 2). Viable receptors are transported out of the ER (Step 3) and sorted through the secretory compartments while they acquire the final modifications (Step 4). Mature receptors are localization at specific membrane sites (Step 5). Accessory proteins shown in the figure coordinate the diverse steps in the transport of receptors.
HRD3/EBS5 IS AN ER MEMBRANE-LOCALIZED GLYCOPROTEIN WITH A ROLE IN THE DEGRADATION OF DEFECTIVE BRI1

A biochemical screen for mutations that affect the ERQC of BRI19 identified ebs5 (Su et al., 2011). Ebs5 encodes the Arabidopsis homolog of the yeast HRD3 which function at the ER-cytosol interface in coordinating ER-associated protein degradation. Both BRI1-9 and BRI1-5 accumulated at higher levels in ebs5 - likely a consequence of a block in degradation of mutated BRI1 isoforms. EBS5 was found to co-immunoprecipitate with both BRI1-5 and BRI1-9, indicative of its affinity for misfolded proteins and role in the ERQC.

P97/CDC48A, AN AAA FAMILY ATPase INTERACTS WITH SERK1 IN THE ER

The ATPase CDC48A was found in a screen for interaction partners of SERK1 (Karlova et al., 2006). Direct physical interaction between CDC48A and the C-terminal kinase domain of SERK1 was demonstrated in both Arabidopsis mesophyll protoplasts and yeast (Rienties et al., 2005; Aker et al., 2006). Although both CDC48A and SERK1 co-localize at the ER and PM, CDC48ASERK1 complexes seem to assemble only in ER structures adjacent to the PM. The function of the CDC48A-SERK1 interaction is unclear. Considering the roles of animal CDC48A in ER and Golgi membrane fusion, and vesicle trafficking (Bae et al., 2009) CDC48A-SERK1 interaction with SERK1 was predicted to assist in receptor maturation.

In addition to the proteins described above, known to establish physical interactions with PM receptors, other components of the ERQC or ER glycosylation machineries play a part in receptor processing at the ER. Genetic screens have identified multiple components necessary in the biosynthesis of EFR, a PM receptor that binds bacterial Ef-Tu (Li et al., 2009; Lu et al., 2009; Nekrasov et al., 2009; Haweker et al., 2010; Saijo, 2010) (Table 1). 


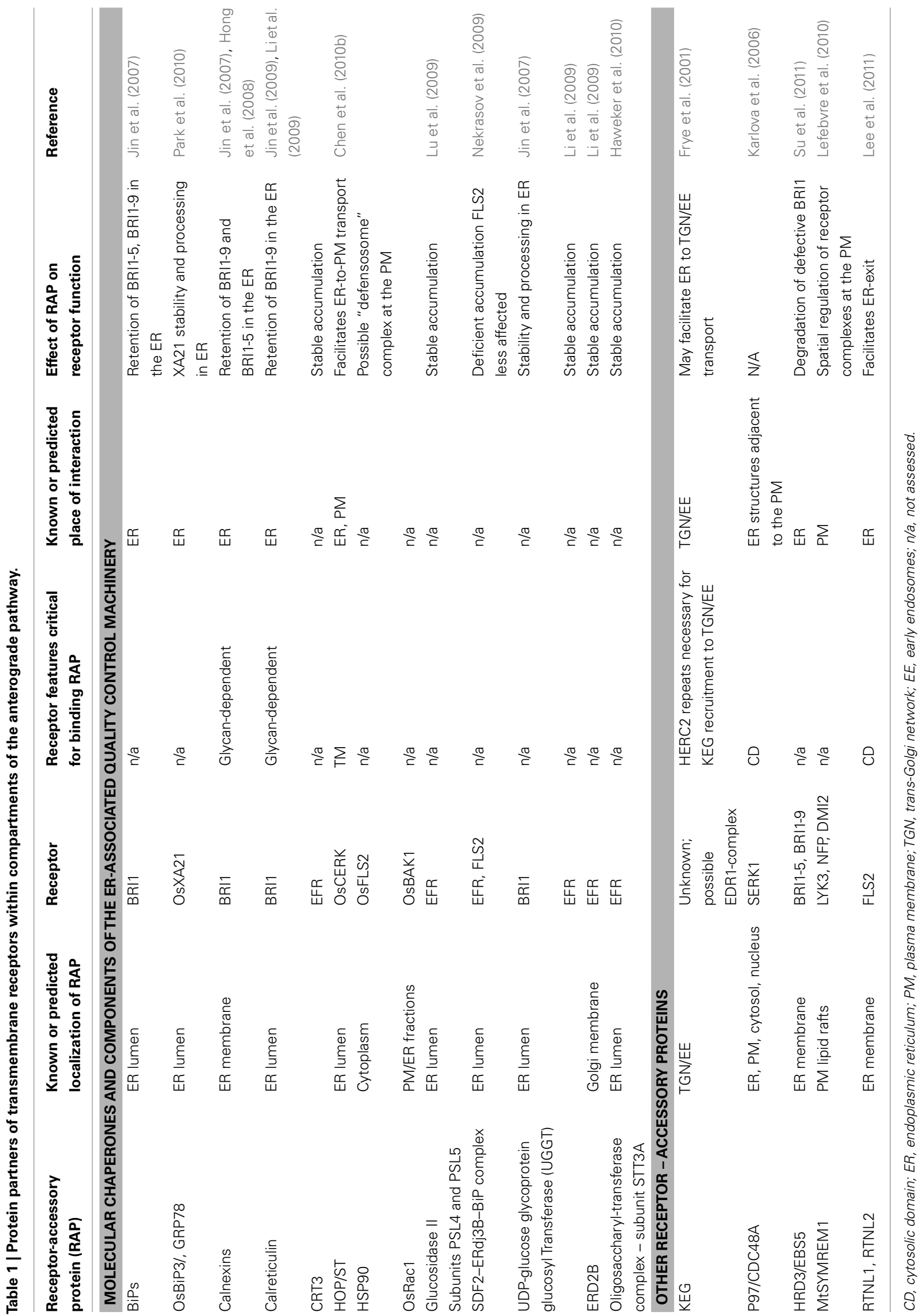


From the above studies, it is evident that ER occupies a key position among the membranous compartments of the secretory transport route. The first steps in receptor biogenesis including polypeptide folding, initial PTM modifications and the quality control mechanisms that ensure correct processing, are facilitated by proteins with diverse activities and are prerequisites for the guidance of new PM receptors out of the ER.

\section{TRANSPORT OF PM RECEPTORS OUT OF THE ENDOPLASMIC RETICULUM AND INTO THE SECRETORY PATHWAY}

In animals, the coordination between receptor transport and cellular signaling output is achieved through interactions of PM receptors with receptor-accessory proteins (RAPs) located in compartments of the anterograde transport pathway. RAPs regulate receptor accumulation at the cell surface and distribution in active PM microdomains (McLatchie et al., 1998; Petaja-Repo et al., 2000; Bermak et al., 2001; Cooray et al., 2009; Díaz, 2010). Similar mechanisms can be envisioned to exist in plants. So far, several proteins were found to influence receptor signaling, and therefore, have the potential to act like animal RAPs: the reticulon-like proteins RTNLB1 and RTNLB2 and the remorin MtSYREM1. A possible addition to this group is the multi-domain protein KEG. Current evidence for the role of plant RAPs (Table 1) in coordinating receptor transport, $\mathrm{PM}$ distribution and function is discussed below.

\section{RETICULONS CONTROL THE TRANSPORT OF FLS2 OUT OF THE ER AND FLS2 SIGNALING ACTIVITY}

A search for proteins that interact with the cytosolic domain of FLS2 identified the reticulon-like protein RTNLB1 (Lee et al., 2011). FLS2 was subsequently shown to interact in vivo with both RTNLB1 and its homolog RTNLB2. Both RTNLB1 and RTNLB2 were found to regulate the functional expression of FLS2 at the PM by facilitating its maturation and transport out of the ER. In plants with defective RTNLB1 and/or RTNLB2 expression, FLS2 accumulation at the PM and FLS2-dependent activation of signaling pathways were impaired. Although an interaction between RTNLB1 or RTNLB2 and EFR was not detected, EFRdependent signaling was negatively influenced in the mutants, suggesting that RTNLB1 and RTNLB2 may assist additional receptors and, thus, coordinate multiple receptor signaling pathways.

\section{A REMORIN PREDICTED TO ACT AS A SCAFFOLD FOR SYMBIOTIC RECEPTORS}

Using in situ immunofluorescence, MtSYREM1 from the remorin family, was found localized at the PM and demonstrated to specifically interact in vivo with the symbiotic receptors NFP, LYK3, and DMI2 (Lefebvre et al., 2010). Analysis of loss-of-function mutants suggested a role for MtSYMREM1 in symbiosis, specifically a role in the assembly of signaling complexes at specific PM sites during plant-microbe interactions. Interestingly, LYK3 protein localization and dynamics at the PM changed in response to bacterial infection (Haney et al., 2011), a response that may be mediated by scaffolds such as remorins.

\section{KEG MAY MEDIATE THE INTRACELLULAR LOCALIZATION OF AN EDR1-CONTAINING RECEPTOR COMPLEX}

$K E G$ is a protein with multiple domains including RING E3 ligase, kinase, ankyrin domains, and HERC2-like repeats ( $\mathrm{Gu}$ and Innes, 2011). KEG co-immunoprecipitated with a variant of EDR1 (putative soluble MAP3K with role in defense; Frye et al., 2001). Interestingly, when expressed alone, EDR1 localized to the ER (Christiansen et al., 2011) whereas in the presence of KEG, EDR1 was identified in the TGN/early endosome (Gu and Innes, 2011). The authors suggested that EDR1 is part of a larger receptor complex that localizes in intracellular compartments, and that KEG mediates its trafficking by directly binding to EDR1.

Interestingly, the plant receptor-interacting proteins described above display several common characteristics with the animal RAPs. They (1) possess conserved protein-protein interaction motifs, (2) assemble in homo- and/or hetero-dimers, (3) influence the spatial distribution within organelles and/or at the PM, and (4) modulate the function of PM-associated signaling receptors. These characteristics suggest that plant receptor-interacting proteins link signaling components to the general trafficking machinery. It is likely that mechanisms similar to animals evolved in plants to modulate the selective transport of signaling elements to the cell surface. The synthesis, transport and display of functional signaling receptors at the PM appears as a tightly regulated process that relies on components of the general transport machinery and receptor-specific elements recruited along the secretory route.

\section{CONCLUSION AND PERSPECTIVES}

The direct or indirect interactions discovered thus far between receptors and proteins that are associated with the secretory transport pathway indicate that the biosynthesis and transport of functional receptors is a complex process that requires multiple steps and various activities that function in a step-wise and cooperative manner. In particular, the ER acts as a central hub for the control of biosynthesis and intracellular distribution of signalingcompetent receptors. Furthermore, the ER appears to enable the fine-tuning of signal transduction by RAP-mediated modulation of the cellular concentrations and functions of receptors at their activity sites.

Although we have only a superficial understanding of how receptor spatial and temporal distributions are regulated, the work summarized in this review clarifies the importance of a number of accessory proteins and also raises interesting questions. Future research will reveal to what extent accessory proteins are needed and what other mechanisms may exist in plants for regulating receptor functions. Furthermore, it will be critical to uncover the sequence determinants responsible for the regulation of receptors. Ultimately, understanding how intracellular trafficking controls cellular physiological outcomes will allow us to modulate fundamental plant traits such as growth and response to stress.

\section{ACKNOWLEDGMENTS}

I am grateful to G. Popescu, E. Brauer, D. Singh, and G. Zampogna for the valuable discussions and help with editing the manuscript. 


\section{REFERENCES}

Agarraberes, F. A., and Dice, J. F. (2001). Protein translocation across membranes. Biochim. Biophys. Acta 1513, $1-24$.

Aker, J., Borst, J. W., Karlova, R., and de Vries, S. (2006). The Arabidopsis thaliana AAA protein CDC48A interacts in vivo with the somatic embryogenesis receptor-like kinase 1 receptor at the plasma membrane. J. Struct. Biol. 156, 62-71.

Aker, J., and de Vries, S. C. (2008). Plasma membrane receptor complexes. Plant Physiol. 147, 1560-1564.

Ascano, M., Richmond, A., Borden, P., and Kuruvilla, R. (2009). Axonal targeting of Trk receptors via transcytosis regulates sensitivity to neurotrophin responses. J. Neurosci. 29, 11674-11685.

Bae, H., Choi, S., Yang, S. W., Pai, H. S., and Kim, W. T. (2009). Suppression of the ER-localized AAA ATPase NgCDC48 inhibits tobacco growth and development. Mol. Cells 28, 57-65.

Bermak, J. C., Li, M., Bullock, C., and Zhou, Q. Y. (2001). Regulation of transport of the dopamine D1 receptor by a new membraneassociated ER protein. Nat. Cell Biol. 3, 492-498.

Bethani, I., Skanland, S. S., Dikic, I., and Acker-Palmer, A. (2010). Spatial organization of transmembrane receptor signalling. EMBO J. 29, 2677-2688.

Boller, T., and Felix, G. (2009). A renaissance of elicitors: perception of microbe-associated molecular patterns and danger signals by patternrecognition receptors. Annu. Rev. Plant Biol. 60, 379-406.

Boutrot, F., Segonzac, C., Chang, K. N., Qiao, H., Ecker, J. R., Zipfel, C., and Rathjen, J. P. (2010). Direct transcriptional control of the Arabidopsis immune receptor FLS2 by the ethylene-dependent transcription factors EIN3 and EIL1. Proc. Natl. Acad. Sci. U.S.A. 107, 14502-14507.

Brandizzi, F., Snapp, E. L., Roberts, A. G., Lippincott-Schwartz, J., and Hawes, C. (2002). Membrane protein transport between the endoplasmic reticulum and the golgi in tobacco leaves is energy dependent but cytoskeleton independent: evidence from selective photobleaching. Plant Cell 14, 1293-1309.

Cai, Y., Jia, T., Lam, S. K., Ding, Y., Gao, C., San, M. W., Pimpl, P., and Jiang, L. (2011). Multiple cytosolic and transmembrane determinants are required for the trafficking of
SCAMP1 via an ER-Golgi-TGNPM pathway. Plant J. 65, 882-896.

Carter, C. J., Bednarek, S. Y., and Raikhel, N. V. (2004). Membrane trafficking in plants: new discoveries and approaches. Curr. Opin. Plant Biol. 7, 701-707.

Chen, F., Gao, M.-J., Miao, Y.-S., Yuan, Y.-X., Wang, M.-Y., Li, Q., Mao, B.-Z., Jiang, L.-W., and He, Z.-H. (2010a). Plasma membrane localization and potential endocytosis of constitutively expressed xa21 proteins in transgenic rice. Mol. Plant 3, 917-926.

Chen, L., Hamada, S., Fujiwara, M., Zhu, T., Thao, N. P., Wong, H. L., Krishna, P., Ueda, T., Kaku, H., Shibuya, N., Kawasaki, T., and Shimamoto, K. (2010b). The Hop/Sti1-Hsp90 chaperone complex facilitates the maturation and transport of a PAMP receptor in rice innate immunity. Cell Host Microbe 7, 185-196.

Christiansen, K. M., Gu, Y., Rodibaugh, N., and Innes, R. W. (2011). Negative regulation of defence signalling pathways by the EDR1 protein kinase. Mol. Plant Pathol. 12, 746-758.

Cooray, S. N., Chan, L., Webb, T. R., Metherell, L., and Clark, A. J. (2009). Accessory proteins are vital for the functional expression of certain $G$ protein-coupled receptors. Mol. Cell. Endocrinol. 300, 17-24.

Díaz, E. (2010). Regulation of AMPA receptors by transmembrane accessory proteins. Eur. J. Neurosci. 32, 261-268.

Dunkley, T. P., Hester, S., Shadforth, I. P., Runions, J., Weimar, T., Hanton, S. L., Griffin, J. L., Bessant, C., Brandizzi, F., Hawes, C., Watson, R. B., Dupree, P., and Lilley, K. S. (2006). Mapping the Arabidopsis organelle proteome. Proc. Natl. Acad. Sci. U.S.A. 103, 6518-6523.

Frye, C. A., Tang, D., and Innes, R. W. (2001). Negative regulation of defense responses in plants by a conserved MAPKK kinase. Proc. Natl. Acad. Sci. U.S.A. 98, 373-378.

Gu, Y., and Innes, R. W. (2011). The keep on going protein of Arabidopsis recruits the enhanced disease resistancel protein to trans-Golgi network/early endosome vesicles. Plant Physiol. 155, 1827-1838.

Hala, M., Cole, R., Synek, L., Drdová, E., Pecenková, T., Nordheim, A., Lamkemeyer, T., Madlung, J., Hochholdinger, F., Fowler, J. E., and Zárský, V. (2008). An exocyst complex functions in plant cell growth in Arabidopsis and tobacco. Plant Cell 20, 1330-1345.
Haney, C. H., Riely, B. K., Tricoli, D. M., Cook, D. R., Ehrhardt, D. W. and Long, S. R. (2011). Symbiotic rhizobia bacteria trigger a change in localization and dynamics of the Medicago truncatula receptor kinase LYK3. Plant Cell 23, 2774-2787.

Harter, K., and Witthhoft, J. (2011). Latest news on Arabidopsis brassinosteroid perception and signaling. Front. Plant Sci. 2:58 doi:10.3389/fpls.2011.00058

Haweker, H., Rips, S., Koiwa, H. Salomon, S., Saijo, Y., Chinchilla, D. Robatzek, S., and von Schaewen, A. (2010). Pattern recognition receptors require $\mathrm{N}$-glycosylation to mediate plant immunity. J. Biol. Chem. 285, 4629-4636.

Hong, Z., Jin, H., Tzfira, T., and Li, J. (2008). Multiple mechanismmediated retention of a defective brassinosteroid receptor in the endoplasmic reticulum of Arabidopsis. Plant Cell 20, 3418-3429.

Jin, H., Hong, Z., Su, W., and Li, J. (2009). A plant-specific calreticulin is a key retention factor for a defective brassinosteroid receptor in the endoplasmic reticulum. Proc. Natl. Acad. Sci. U.S.A 106, 13612-13617.

Jin, H., Yan, Z., Nam, K. H., and Li, J. (2007). Allele-specific suppression of a defective brassinosteroid receptor reveals a physiological role of UGGT in ER quality control. $\mathrm{Mol}$. Cell 26, 821-830.

Jurgens, G. (2004). Membrane trafficking in plants. Annu. Rev. Cell Dev. Biol. 20, 481-504.

Karlova, R., Boeren, S., Russinova, E., Aker, J., Vervoort, J., and de Vries, S. (2006). The Arabidopsis somatic embryogenesis receptor-like kinase1 protein complex includes brassinosteroid-insensitive1. Plant Cell 18, 626-638.

Kevany, B. M., Taylor, M. G., and Klee, H. J. (2008). Fruit-specific suppression of the ethylene receptor LeETR4 results in early-ripening tomato fruit. Plant Biotechnol. J. 6, 295-300.

Kleizen, B., and Braakman, I. (2004). Protein folding and quality control in the endoplasmic reticulum. Curr. Opin. Cell Biol. 16, 343-349.

Lee, H. Y., Bowen, C. H., Popescu, G. V., Kang, H. G., Kato, N., Ma, S., DineshKumar, S., Snyder, M., and Popescu, S. C. (2011). Arabidopsis RTNLB1 and RTNLB2 reticulon-like proteins regulate intracellular trafficking and activity of the FLS2 immune receptor. Plant Cell 23, 3374-3391.

Lefebvre, B., Timmers, T., Mbengue, M., Moreau, S., Hervé, C., Tóth, K.,
Bittencourt-Silvestre, J., Klaus, D., Deslandes, L., Godiard, L., Murray, J. D., Udvardi, M. K., Raffaele, S., Mongrand, S., Cullimore, J., Gamas, P., Niebel, A., and Ott, T. (2010). A remorin protein interacts with symbiotic receptors and regulates bacterial infection. Proc. Natl. Acad. Sci. U.S.A. 107, 2343-2348.

Li, J., and Chory, J. (1997). A putative leucine-rich repeat receptor kinase involved in brassinosteroid signal transduction. Cell 90, 929-938.

Li, J., Zhao-Hui, C., Batoux, M., Nekrasov, V., Roux, M., Chinchilla D., Zipfel, C., and Jones, J. D. (2009). Specific ER quality control components required for biogenesis of the plant innate immune receptor EFR. Proc. Natl Acad. Sci. U.S.A. 106, 15973-15978.

Lu, X., Tintor, N., Mentzel, T., Kombrink, E., Boller, T., Robatzek, S. Schulze-Lefer, P., and Saijo, Y. (2009). Uncoupling of sustained MAMP receptor signaling from early outputs in an Arabidopsis endoplasmic reticulum glucosidase II allele. Proc. Natl. Acad. Sci. U.S.A. 106, 22522-22527.

McLatchie, L. M., Fraser, N. J., Main, M. J., Wise, A., Brown, J., Thompson, N., Solari, R., Lee, M. G., and Foord, S. M. (1998). RAMPs regulate the transport and ligand specificity of the calcitoninreceptor-like receptor. Nature 393, 333-339.

Mellman, I., and Nelson, W. J. (2008). Coordinated protein sorting, targeting and distribution in polarized cells. Nat. Rev. Mol. Cell Biol. 9, 833-845.

Mersmann, S., Bourdais, G., Rietz, S., and Robatzek, S. (2010). Ethylene signaling regulates accumulation of the FLS2 receptor and is required for the oxidative burst contributing to plant immunity. Plant Physiol. 154, 391-400.

Molinari, M., and Helenius, A. (2000). Chaperone selection during glycoprotein translocation into the endoplasmic reticulum. Science 288 , 331-333.

Nekrasov, V., Li, J., Batoux, M., Roux, M., Chu, Z. H., Lacombe, S., Rougon, A., Bittel, P., Kiss-Papp, M., Chinchilla, D., van Esse, H. P., Jorda, L., Schwessinger, B., Nicaise, V., Thomma, B. P., Molina, A., Jones, J. D., and Zipfel, C. (2009). Control of the pattern-recognition receptor EFR by an ER protein complex in plant immunity. EMBO J. 28, 3428-3438.

Park, C.-J., Bart, R., Chern, M., Canlas, P. E., Bai, W., and Ronald, P. C. (2010). 
Overexpression of the endoplasmic reticulum chaperone $\mathrm{BiP} 3$ regulates XA21-mediated innate immunity in rice. PLoS ONE 5, e9262. doi:10.1371/journal.pone.0009262

Petaja-Repo, U. E., Hogue, H., Laperriere, A., Walker, P., and Bouvier, M. (2000). export from the endoplasmic reticulum represents the limiting step in the maturation and cell surface expression of the human opioid receptor. J. Biol. Chem. 275, 13727-13736.

Rapoport, T. A. (2007). Protein translocation across the eukaryotic endoplasmic reticulum and bacterial plasma membranes. Nature 450, 663-669.

Reddy, P. S., and Corley, R. B. (1998). Assembly, sorting, and exit of oligomeric proteins from the endoplasmic reticulum. Bioessays 20, 546-554.

Rienties, I. M., Vink, J., Borst, J. W., Russinova, E., and de Vries, S. C. (2005). The Arabidopsis SERK1 protein interacts with the AAA-ATPase CDC48, the 14-33 protein GF14 $\lambda$ and the $\mathrm{PP} 2 \mathrm{C}$ phosphatase KAPP. Planta 221, 394-405.
Rojo, E., and Denecke, J. (2008). What is moving in the secretory pathway of plants? Plant Physiol. 147, 1493-1503.

Runions, J., Brach, T., Kühner, S., and Hawes, C. (2006). Photoactivation of GFP reveals protein dynamics within the endoplasmic reticulum membrane. J. Exp. Bot. 57, 43-50.

Saijo, Y. (2010). ER quality control of immune receptors and regulators in plants. Cell. Microbiol. 12, 716-724.

Shilo, B.-Z., and Schejter, E. D. (2011). Regulation of developmental intercellular signalling by intracellular trafficking. EMBO J. 30, 3516-3526.

Smith, M. H., Ploegh, H. L., and Weissman, J. S. (2011). Road to ruin: targeting proteins for degradation in the endoplasmic reticulum. Science 334, 1086-1090.

Staehelin, L. A., and Kang, B.-H. (2008). Nanoscale architecture of endoplasmic reticulum export sites and of golgi membranes as determined by electron tomography. Plant Physiol. 147, 1454-1468.

Stefano, G., Renna, L., Chatre, L., Hanton, S. L., Moreau, P., Hawes, C., and Brandizzi, F. (2006). In tobacco leaf epidermal cells, the integrity of protein export from the endoplasmic reticulum and of ER export sites depends on active COPI machinery. Plant J. 46, 95-110.

Su, W., Liu, Y., Xia, Y., Hong, Z., and Li, J. (2011). Conserved endoplasmic reticulum-associated degradation system to eliminate mutated receptor-like kinases in Arabidopsis. Proc. Natl. Acad. Sci. U.S.A. 108, 870-875.

Tor, M., Lotze, M. T., and Holton, N. (2009). Receptor-mediated signalling in plants: molecular patterns and programmes. J. Exp. Bot. 60, 3645-3654.

van Esse, G. W., Westphal, A. H., Surendran, R. P., Albrecht, C., van Veen, B., Borst, J. W., and de Vries, S. C. (2011). Quantification of the BRI1 receptor in planta. Plant Physiol. 156, 1691-1700.

Winckler, B., and Mellman, I. (2010). Trafficking guidance receptors. Cold Spring Harb. Perspect. Biol. 2, 1-18.

Zhang, Y., Liu, C.-M., Emons, A. M., and Ketelaar, T. (2010). The plant exocyst. J Integr Plant Biol 52, 138-146.
Zipfel, C. (2008). Pattern-recognition receptors in plant innate immunity. Curr. Opin. Immunol. 20, 10-16.

Conflict of Interest Statement: The author declares that the research was conducted in the absence of any commercial or financial relationships that could be construed as a potential conflict of interest.

Received: 16 January 2012; accepted: 26 March 2012; published online: 13 April 2012.

Citation: Popescu SC (2012) A model for the biosynthesis and transport of plasma membrane-associated signaling receptors to the cell surface. Front. Plant Sci. 3:71. doi: 10.3389/fpls.2012.00071

This article was submitted to Frontiers in Plant Proteomics, a specialty of Frontiers in Plant Science.

Copyright (c) 2012 Popescu. This is an open-access article distributed under the terms of the Creative Commons Attribution Non Commercial License, which permits non-commercial use, distribution, and reproduction in other forums, provided the original authors and source are credited. 